УДК 631.4

\title{
ОПРЕДЕЛЕНИЕ ВЛИЯНИЯ ЗАПАДИННЫХ КОМПЛЕКСОВ НА СПОСОБНОСТЬ ПОЧВ К ВОСПРОИЗВОДСТВУ ПЛОДОРОДИЯ
}

\author{
К.Ю. Зотова, К.Е. Стекольников \\ Воронежский государственный аграрный университет им. императора Петра I, Воронеж, Россия \\ Эл. nочта: kristina-zotova26@rambler.ru \\ Статья поступила в редакичию 15.02.2020; принята к печати 29.05.2020
}

Западины (бессточные понижения рельефа) широко распространены на Окско-Донской равнине. Проведен анализ почв западинных комплексов Верхнехавского района Воронежской области, определены их состав и физико-химические свойства, а также выявлена степень гидроморфизма с целью определить необходимость мероприятий для продуктивного сельскохозяйственного использования пахотных земель, а также оценить влияние западинных комплексов на возможность почв к воспроизводству. Выявлены причины негативного влияния западинных комплексов на состояние пахотных земель и предложены пути их устранения.

Ключевые слова: западинные комплексы, природные факторы, гидроморфизм, антропогенные факторы, пахотные угодья.

\section{DETERMINATION OF THE INFLUENCE OF DRANLESS DEPRESSIONS OF RELIEF ON THE SUSTAINABILITY OF SOIL FERTILITY}

\author{
K.Yu. Zotova ${ }^{1}$, K.Ye. Stekolnikov \\ Emperor Peter the First Voronezh State Agrarian University, Voronezh, Russia \\ E-mail: kristina-zotova26@rambler.ru
}

Drainless depressions of relief are usual for plains between the rivers Don and Oka. Soils in such depressions located in Verkhnekhavsky district of Voronezh District were studied to assess (i) their physicochemical characteristics and the degree of their hydromorphicity in order to determine the rational for measures aimed at making them suitable for agriculture and (ii) the effect of such depression on the sustainability of soil fertility. Several causes of the negative effects of depressions on arable lands are delineated and approaches to their reduction are suggested.

Keywords: drainless depressions of relief, natural factors, hydromorphicity, anthropogenic factors, arable lands.

\section{ВВЕДЕНИЕ}

Для Окско-Донской равнины характерно широкое распространение так называемых западинных комплексов луговочерноземных почв, которые приурочены к замкнутым бессточным понижениям. Западины - бессточные понижения рельефа, весьма многообразны по форме, глубине вреза и площади. Глубина вреза варьирует от нескольких десятков сантиметров до 13 метров, площадь - от десятков квадратных метров до 5-10 гектаров, а их доля в пашне от единичных доходит до 20-50\% и более (рис. 1).

Избыточное поверхностное увлажнение существенно затрудняет сельскохозяйственное использование этих комплексов, так как физико-химические свойства почв обусловлены высокой степенью гидроморфизма.

На территории Окско-Донской равнины в пределах Воронежской области западинные комплексы широко распространены на черноземно-луговых и лугово-черноземных почвах. В Воронежской области больше всего таких комплексов наблюдается в Верхнехавском, Панинском, Новоусманском и Эртильском, Боброском, Аннинском и Таловском районах [2]. Следует отметить, что в этих районах (кроме Бобровского) сохранились черноземы со средневзвешенным содержанием гумуса выше 7\%. Однако при наличии самых плодородных земель использовать их в полной мере достаточно сложно. Это связано с длительным затоплением (переувлажнением) почв западинных комплексов.

Степень и длительность затопления (переувлажнения) западин зависит от количества осадков. Например, в годы с большим количеством осадков, особенно в ранневесенний период, наблюдается затопление и микро-, и макро-западин, которое происходит из-за большого количества талых вод на поверхности, а также из-за повышения уровня грунтовых вод. Вследствие этого и вся периферия западин оказывается переувлажненной длительное время, что не позволяет подготовить почвы к посеву сельскохозяйственных культур, и впоследствии такая территория зарастает сорной растительностью. Поверхностное переувлажнение существенно осложняет выращивание основной для Воронежской области продовольственной культуры озимой пшеницы. Вследствие поверхностного увлажнения западин озимая пшеница часто вымокает и выпревает. Но в годы с нормальным или дефицитным увлажнением эта территория из-за большего увлажнения за счет перераспределения атмосферной влаги даже выигрывает по сравнению с плакорами и способствует получению высоких урожаев сельскохозяйственных культур. 


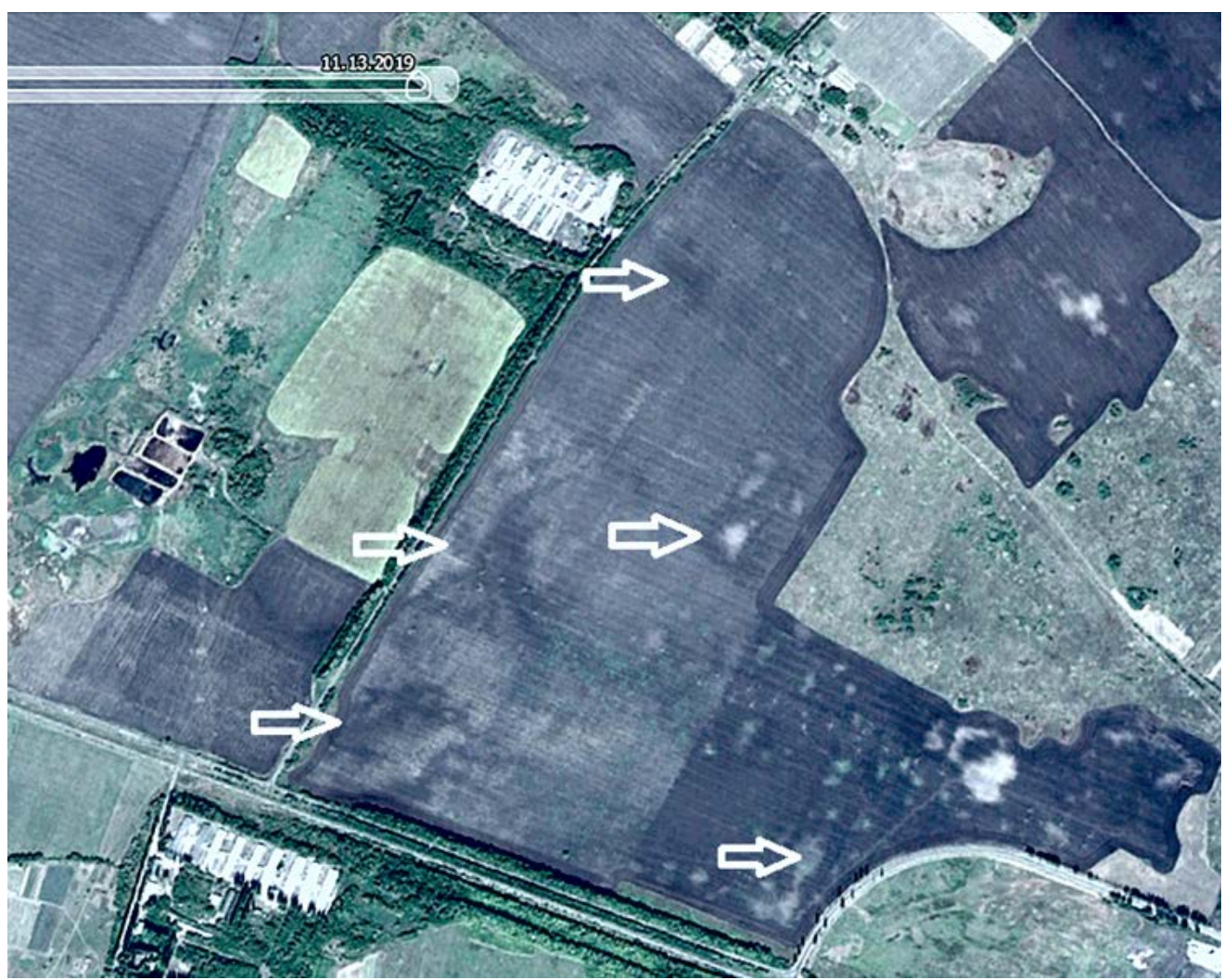

Рис. 1. Западины на участке территории Верхнехавского района Воронежской области

Несмотря на длительную историю изучения западин, гидроморфных и полугидроморфных почв, их генезис остается мало изученным. Они широко распространены на плоских слабо дренированных и недренированных водоразделах лесостепи Центрально-Черноземного района (ЦЧР). Их разнообразие и распространение были выявлены во второй половине ХХ в. Особую роль в их изучении сыграли работы Е.М. Самойловой. Впервые в своей монографии Е.М. Самойлова обобщила данные по проблеме генезиса и классификации рационального использования почв западинных комплексов лесостепи ЦЧР, а также сделала заключение о существенном участии черноземно-луговых почв в структуре почвенного покрова Окско-Донской равнины [4]. Она ориентировочно оценила их площадь в 100 тыс. га. По мнению Е.Н. Ивановой, черноземно-луговые почвы приурочены к межколочным пониженным пространствам, входя в состав «сочетаний из луговых почв и дерновых глеевых солодей и комплексов из луговых почв и солончаковых или солончаковатых луговых солонцов» [3]. В пределах Среднерусского Черноземья особое значение по изучению этих почв имеют работы Б.П. Ахтырцева и А.Б. Ахтырцева [1].

\section{Объекты и методы исследования}

В Воронежской области наибольшее число западинных комплексов отмечено в Северо-Восточной части, которая относится к лесостепной зоне Окско-Донской равнины. В качестве объекта исследования нами выбран один из типичных районов области, находящийся в зоне переувлажнения, - Верхнехавский. Исследования выполнены в сентябре 2019 г. Для изучения морфологии, состава и физико-химических свойств были заложены 4 почвенных разреза на пахотных угодьях, а также использовались образцы, отобранные на целинной западине с кустарниковой и луговой растительностью.

В лабораторных исследованиях использовались следующие стандартные методы:

о рН водной и солевой вытяжки - потенциометрия;

о гидролитическая кислотность - по Каппену с потенциометрическим окончанием (ОСТ 46 48-76);

о гумус - фотометрия по ОСТ 46 47-76;

о подвижный фосфор и обменный калий - по Чирикову;

о нитраты - потенциометрия;

o аммонийный азот - фотометрия. 


\section{Результаты и обсуждение}

Результаты представлены в табл. 1.

Табл. 1

Состав и свойства исследованных почв

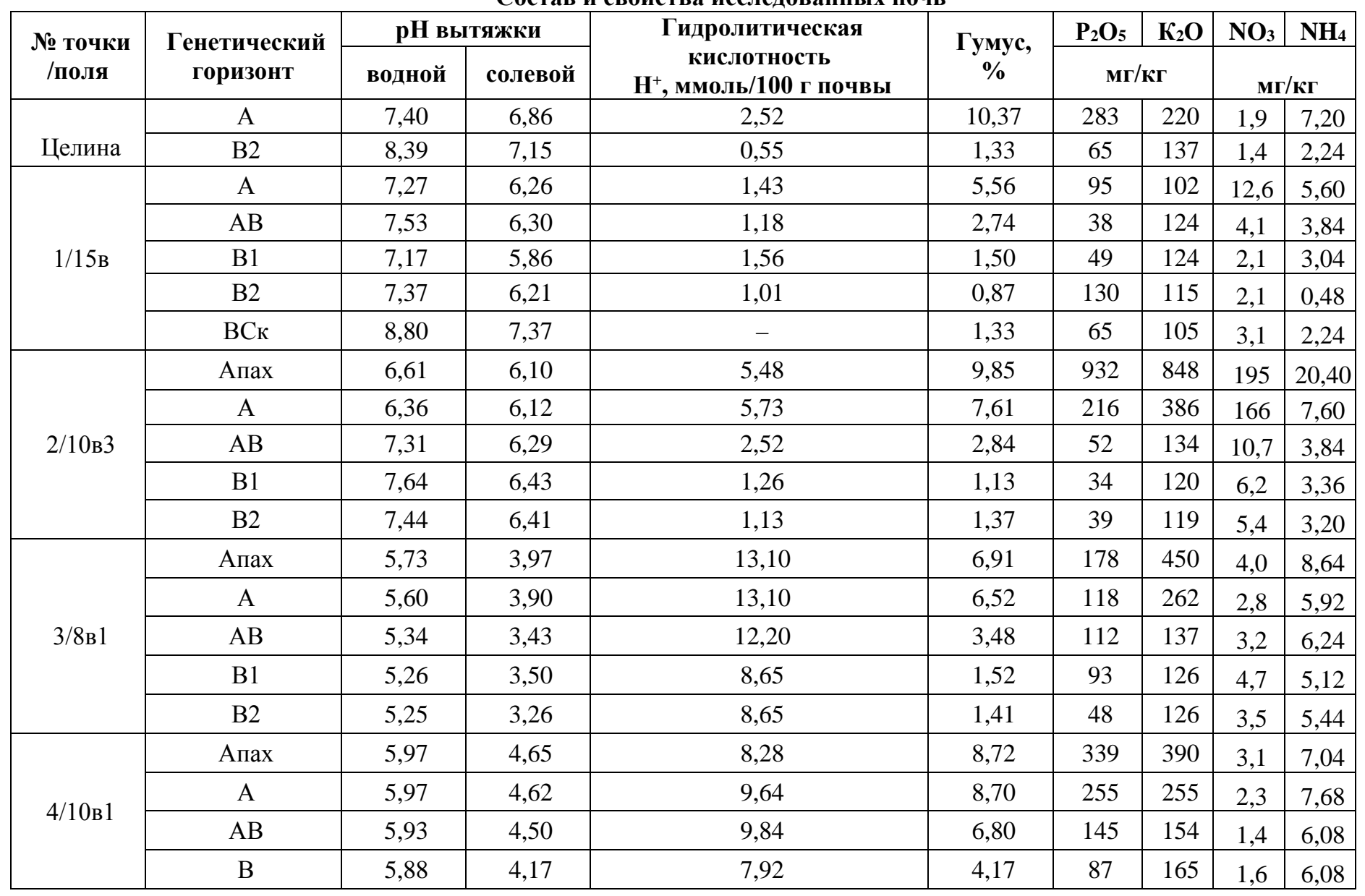

Особый интерес представляют свойства почвы на нераспаханной части западины - целине. Растительность ее представлена кустарниками и разнотравным лугом. В пределах гумусового горизонта наблюдаются значительные колебания $\mathrm{pH}$ водной и солевой вытяжек в гумусовом и иллювиальном горизонтах $-7,40$ и 8,39, 6,86 и 7,15 соответственно. Также важно обратить внимание на изменение величины гидролитической кислотности, значения которой в горизонте А в 4,5 раза больше, чем в горизонте В2, и составляют 2,52 и 0,55 ммоль/100 г почвы, соответственно. Что касается содержания гумуса, то его колебания в рассматриваемых горизонтах значительны. Так, в гумусовом горизонте содержание достигает 10,37\% (максимум во всех разрезах), а в иллювиальном - $1,33 \%$, что в 7,8 раза ниже показателя гумусового горизонта.

Целинный участок использован для сравнения характеристик изучаемых почв. Так как он не подвержен антропогенному влиянию, уровень плодородия почвы очень высок, о чем свидетельствует очень высокое содержание гумуса - 10,37\%. В пахотном слое почвы с таким содержанием гумуса отсутствуют. Так как почва не подвержена механической обработке, сохранилась прекрасная зернистая структура, характерная для черноземных почв. На пашне она практически утрачена, и для ее воспроизводства потребуются очень высокие дозы органических удобрений высокого качества, прежде всего, навоза крупного рогатого скота, а его в области практически нет.

Навоз на современных животноводческих фермах малопригоден для восстановления уровня гумуса черноземов. Это обусловлено технологией удаления навоза. Он удаляется гидросмывом, доля воды в нем достигает 90\% и более (по ГОСТу в навозе крупного рогатого скота доля воды не должна превышать 80\%). Ценность жидкой фракции очень низкая, а вывозить ее на поля экономически нецелесообразно. Целинный участок имеет очень высокую степень обеспеченности подвижными формами фосфора и обменного калия в верхней части гумусового профиля - 283 и 220 мг/кг почвы. Вниз по профилю содержание их резко снижается. Реакция среды нейтральная, а величина гидролитической кислотности невелика. Степень 
обеспеченности минеральными формами азота низкая, что обусловлено интенсивным потреблением его мощной травянистой растительностью.

Следует отметить, что разрезы закладывались на западинах с различной глубиной вреза, что позволяло выявить как степень поверхностного переувлажнения, так и его влияние на свойства изучаемых почв. Анализируя полученные данные по разрезу 1 , который был заложен на лугово-черноземной почве в хорошо выраженной плоской западине, в 150 м от целинного участка, мы отмечаем высокую величину $\mathrm{pH}$ водной вытяжки по всему профилю. Скорее всего, это обусловлено миграционными формами карбонатов, тем более что в горизонте ВСк карбонаты определяются уже визуально. Величина обменной кислотности, характеризуемая $\mathrm{pH}$ солевой вытяжки, изменяется по профилю в довольно широком диапазоне от 6,26 в пахотном слое до 7,37 в горизонте ВСк. Минимальные величины рН водной и солевой вытяжек наблюдаются в горизонте В1. Нейтральная среда по всему профилю обусловлена и низкой величиной гидролитической кислотности, варьирующей по профилю в пределах 1,43-1,01, с максимумом в горизонте В1 - 1,56 ммоль/100 г почвы.

Данная почва по содержанию гумуса - от 2,74 до 5,56\% - относится к малогумусной. Характер распределения гумуса по профилю соответствует прогрессивно убывающему типу.

Что касается разреза 2, то он заложен на поле под паром, на слабо врезанной западине. Навоз был внесен поверхностно и запахан на глубину 21-25 см. Это повлияло на все показатели физико-химического состояния изучаемой почвы, так как профиль почвы резко дифференцирован. Внесение свиного навоза, имеющего кислую реакцию, понизило величину рН водной и солевой вытяжек, если их сравнивать с таковыми на целине. Реакция среды нейтральная в пахотном слое и верхней части гумусового горизонта, и она резко возрастает в нижележащих горизонтах. Подобная дифференциация профиля обусловлена, прежде всего, внесением очень высокой дозы (100-150 м³/га) свиного навоза. Такой вывод подтверждается и по остальным показателям. Величина гидролитической кислотности в пахотном слое и горизонте А достигает 5,73 и резко снижается в горизонте АВ до 2,52 ммоль/100 г почвы. Столь же резкая дифференциация профиля наблюдается и по содержанию гумуса. Максимальное содержание его отмечается в пахотном слое - 9,85\%, в горизонте А оно снижается до 7,61\%, а в горизонте АВ снижается до 2,84\%. Распределение гумуса по профилю соответствует прогрессивно убывающему типу.

Разрез 3 заложен в хорошо выраженной западине под озимой пшеницей. Дополнительное увлажнение за счет стока атмосферной влаги в западину обусловливает существенное выщелачивание профиля от карбонатов. Об этом свидетельствуют самые низкие величины $\mathrm{pH}$ водной и солевой вытяжек по всему профилю - 5,73-5,25 и 3,97-3,26\% соответственно. Это подтверждается и величиной гидролитической кислотности. В гумусовом горизонте она варьирует в пределах 13,10-12,20 ммоль/100 г почвы и снижается в иллювиальных горизонтах до 8,65 ммоль/100 г почвы. Устранить избыточную кислотность можно только известкованием. Расчетная доза извести для пахотного слоя составит 19,65 т/га в действующем веществе. Это очень затратное мероприятие, однако его можно существенно удешевить, если проводить не сплошное, а выборочное известкование, то есть непосредственно только по западинам. Тем более что они хорошо видны на пашне (см. рис. 1).

Содержание гумуса варьирует в гумусовом горизонте в пределах 6,91-3,48\%, что соответствует среднему уровню гумусированности. Распределение гумуса по профилю соответствует прогрессивно убывающему типу.

Разрез 4 заложен в хорошо выраженной западине под озимой пшеницей. Дополнительное увлажнение за счет стока атмосферной влаги в западину обусловливает существенное выщелачивание профиля от карбонатов. Об этом свидетельствуют низкие величины $\mathrm{pH}$ водной и солевой вытяжек по всему профилю 5,97-5,88 и 4,65-4,17 соответственно. Величина гидролитической кислотности в гумусовом горизонте варьирует в пределах 8,28-9,84 ммоль/100 г почвы и снижается в иллювиальном горизонте до 7,92 ммоль/100 г почвы. Как и для почвы разреза 3, необходимо выборочное известкование. Расчетная доза извести - 12,42 т/га.

Выше отмечена весьма существенная дифференциация профиля изучаемых почв по всем параметрам, в том числе и по содержанию подвижных форм фосфора, обменного калия и минеральным формам азота. Генетически обусловленная дифференциация профиля изучаемых почв усиливается под влиянием высоких доз свиного навоза. Это наглядно показано на рис. 2 и 3.

Как видно на рис. 2, максимальное содержание подвижных форм фосфора и обменного калия наблюдается в пахотном слое разреза 2 - паровое поле после внесения и запашки свиного навоза. Содержание элементов питания согласно существующей градации (см. табл. 2) оценивается не просто как высокое, а превышающее допустимые показатели содержания фосфора в 4,5 и калия в 5 раз. Это связано с очень высокими дозами свиного навоза. Рекомендуется вносить 40-50 м ${ }^{3} / г$. Применяемые в хозяйстве дозы свиного навоза 100-150 м3/га следует считать избыточно высокими. Вниз по профилю содержание этих форм элементов питания резко снижается.

Разрезы 2 и 3 были заложены на полях с озимой пшеницей, размещенной по пару. На рис. 2 видно, что содержание подвижного фосфора и обменного калия в 2-4 раза ниже, чем в паровом поле. Это обусловлено переходом фосфора в менее растворимые формы и потреблением его озимой пшеницей на формирование урожая, фиксацией калия смешанослойными минералами и поглощением его растениями озимой пшеницы. Минимальное содержание подвижных форм фосфора и обменного калия наблюдается на распаханной целине (разрез 1). 


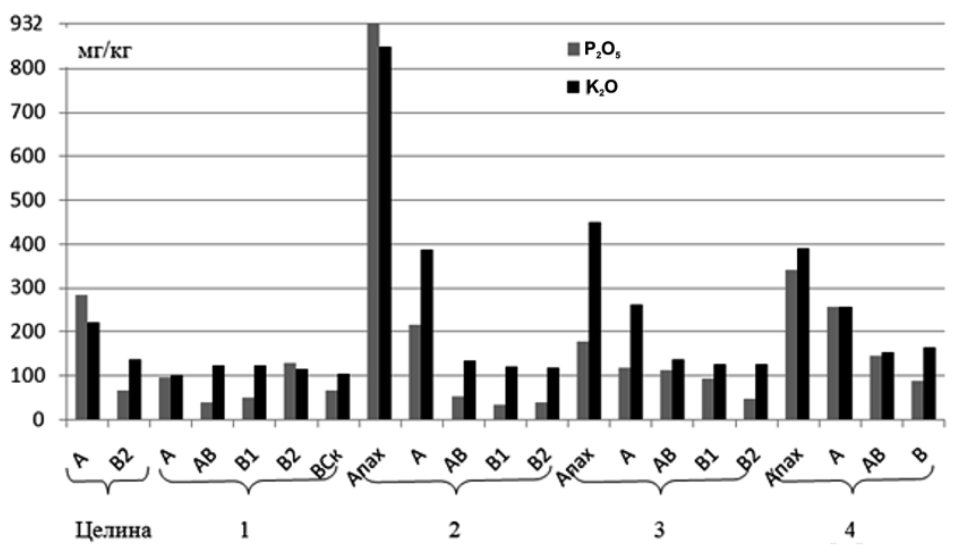

Рис. 2. Распределение подвижного фосфора и обменного калия по профилю почв целины и 4 западинных разрезов

Табл. 2

Группировка почв по содержанию усвояемых форм $\mathrm{P}_{2} \mathrm{O}_{5}$ и $\mathrm{K}_{2} \mathrm{O}$ (по Ф.В. Чирикову) и шкала обеспеченности растений минеральными формами почвенного азота (по Г.П. Гамзикову) [3]

\begin{tabular}{|c|c|c|c|c|c|c|}
\hline \multirow{2}{*}{$\begin{array}{c}\text { Класс } \\
\text { обеспеченности }\end{array}$} & \multirow{2}{*}{$\begin{array}{c}\text { Степень } \\
\text { обеспеченности }\end{array}$} & \multicolumn{2}{|c|}{ Содержание (мг/кг) } & \multicolumn{3}{|c|}{ Интервалы содержания азота (мг/кг) } \\
\hline & & $\mathbf{K}_{2} \mathbf{O}$ & $\mathbf{P}_{2} \mathbf{O}_{5}$ & $\mathrm{~N}\left(\mathrm{NO}_{3}\right)(0-20 \mathrm{~cm})$ & $\mathrm{N}\left(\mathrm{NO}_{3}\right)(0-40 \mathrm{~cm})$ & $\mathrm{N}\left(\mathrm{NO}_{3}\right)+\mathrm{N}\left(\mathrm{NH}_{4}\right)(0-20 \mathrm{~cm})$ \\
\hline 1 & Очень низкая & $<20$ & $<20$ & $<10$ & $<5$ & $<10$ \\
\hline 2 & Низкая & $21-40$ & $21-50$ & $10-15$ & $5-10$ & $10-20$ \\
\hline 3 & Средняя & $41-80$ & $41-100$ & $15-20$ & $10-15$ & $20-40$ \\
\hline 4 & Повышенная & $81-120$ & 101-150 & - & 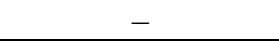 & 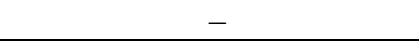 \\
\hline 5 & Высокая & $121-180$ & $151-200$ & $>20$ & $>15$ & $>40$ \\
\hline 6 & Очень высокая & $>180$ & $>200$ & - & - & - \\
\hline
\end{tabular}

Несколько иные закономерности наблюдаются при анализе содержания минеральных форм азота. Свиной навоз, удаляемый гидросмывом, содержит $0,13 \%$ азота, $0,66 \%$ фосфора и $0,07 \%$ калия. Минеральный азот представлен двумя формами, нитратной и аммонийной. Аммонийный азот, как и фосфор с калием, может закрепляться в почве. Нитратный же азот не фиксируется в почве и при избыточном увлажнении мигрирует вниз по профилю и может попасть в грунтовые воды, загрязняя их. На рис. 3 показано содержание и характер распределения по профилю минеральных форм азота.

Согласно шкале оценки содержания нитратного азота (табл. 2) оно в пахотном слое разреза 2 превышает высокую степень обеспеченности в 9,7 раза, а в подпахотном - в 11,1 раза. Вниз по профилю оное резко снижается. Причиной этого может быть дефицит осадков в вегетационном периоде 2019 г. Однако возможна миграция нитратного азота вниз по профилю ранней весной после схода снега и избыточного поверхностного увлажнения. Поэтому возможность загрязнения грунтовых вод нитратами на этом поле вполне реальна.

Обращает на себя внимание неодинаковое соотношение нитратного и аммонийного азота в исследуемых почвах. На целине и в почве разрезов 3 и 4 преобладает аммонийная форма азота, а в разрезах 1 и 2 - нитратная. Скорее всего, преобладание аммонийной формы азота на полях под озимой пшеницей (разрезы 3 и 4) обусловлено повышенной кислотностью, резко снижающей нитрификацию.

Обеспеченность озимой пшеницы минеральными формами азота оценивается в пахотном слое как низкая, а в подпахотном слое - очень низкая. Внесение высоких доз свиного навоза в паровом поле способствует поступлению в почву большого количества минерального азота, который в значительной мере просто теряется за счет миграции нитратов за пределы корнеобитаемого слоя и не работает на формирование высоких урожаев, а поступление нитратов в грунтовые воды загрязняет их.

Тем не менее, высокий уровень потенциального плодородия почв на фоне высоких и сверхвысоких доз свиного навоза позволяет получать урожаи озимой пшеницы на уровне 4-6 т/га. В 2017 г. на отдельных полях урожайность озимой пшеницы превысила 10 т/га. 


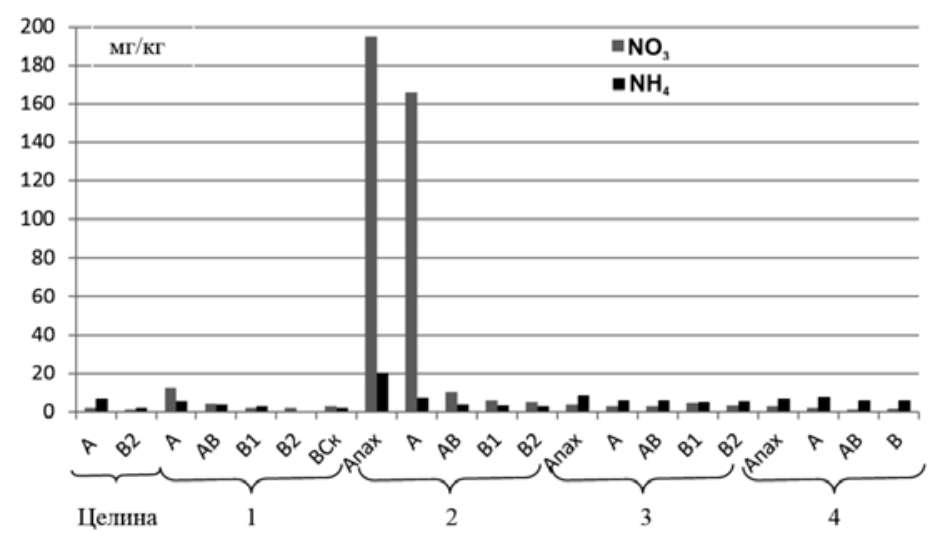

Рис. 3. Содержание и характер распределения минерального азота (мг/кг почвы) по профилям почв целины и четырех разрезов.

\section{ЗАКЛЮЧЕНИЕ}

Установлено, что почвы Верхнехавского района Воронежской области имеют большое число западинных комплексов, при этом они хорошо гумусированы и обладают высоким уровнем потенциального плодородия. Содержание гумуса в гумусовом горизонте варьирует в пределах $10,37-2,74 \%$, а характер распределения гумуса соответствует прогрессивно убывающему типу.

Длительное внутрипочвенное внесение свиного навоза в качестве органического удобрения в дозах $100-150 \mathrm{~m}^{3} /$ га обусловливает сверхвысокое содержание подвижного фосфора и обменного калия. Внесение высоких доз свиного навоза на глубину 20-30 см в паровые поля является эффективным способом воспроизводства плодородия изучаемых почв и получения стабильно высоких урожаев озимой пшеницы. Однако эти дозы свиного навоза экологически не обоснованы, так как предопределяют возможность загрязнения грунтовых вод нитратами и тем самым негативно сказываются как на состоянии земель, так и на способности их к воспроизводству.

Изученные почвы обладают высоким уровнем плодородия, но наличие западин на пашне существенно осложняет выполнение технологических операций по возделыванию сельскохозяйственных культур, затрудняя процесс производства на проблемных территориях не только излишним естественным увлажнением западин (талые воды), но и антропогенным переувлажнением (внесение жидкой фракции навоза). Кроме этого, следует отметить высокий уровень кислотности западин, который оказывает негативное влияние как на возделываемые культуры, так и на состоянии почв в целом. С учетом всех особенностей рассматриваемой территории предложения по устранению указанных проблем такие:

- для снижения кислотности необходимо проведение выборочной химической мелиорации (известкования);

- для устранения переувлажнения земель от весенних паводков (естественного переувлажнения) необходимы работы по переводу поверхностных вод во внутрипочвенные путем щелевания западин;

- для устранения излишнего антропогенного переувлажнения важно снизить дозы внесения жидкой фракции навоза в почву;

- для целостного сохранения воспроизводственного процесса почвенного плодородия необходимы планировка поверхности и работы по землеванию западин.

\section{Список русскоязычной литературы}

\section{ЛИТЕРАТУРА}

1. Ахтырцев АБ. Гидроморфные почвы и переувлажненные земли лесостепи Русской равнины. Воронеж; 2003.

2. Зотова КЮ, Недикова ЕВ. Анализ земельного фонда Верхнехавского района Воронежской области. Инновационные технологии и технические средства для АПК. Материалы Международной научно-практической конференции молодых ученых и специалистов. Воронеж: ВГАУ; 2017;(4):81-4.

3. Иванова ЕН. Классификация почв СССР. М.: Наука; 1976.

4. Самойлова ЕМ. Луговые почвы лесостепи. М.: Изд-во МГУ; 1981.

\section{Общий список литературы/Reference list}

1. Akhtyrtsev AB. Gidromorfnye Pochvy i Pereuvlazhnennye Zemli Lesostepi Russkoy Ravniny. [Hydromorphic Soils and Waterlogged Lands of the Forest-Steppe of the Russian Plain]. Voronezh; 2003. (In Russ.) 
2. Zotova KYu, Netikova YeV. [Analysis of the land fund of the Verkhnekhavsky district of Voronezh Region]. In: Innovatsionnye Tekhnologii i Tekhnicheskiye Sredstva dlia APK. Materialy Mezhdunarodnoy Nauchno-Prakticheskoy Konferentsii Molodykh Uchenykh i Spetsialistov. Voronezh: VGAU; 2017;(4):81-4. (In Russ.)

3. Ivanova YeN. Klassifikatsiya Pochv SSSR. [Classification of Soils of the USSR]. Moscow: Nauka; 1976. (In Russ.)

4. Samoylova YeM. Lugovye Pochvy Lesostepi. [Meadow Soils of Forest-Steppe]. Moscow: MGU; 1981. (In Russ.)
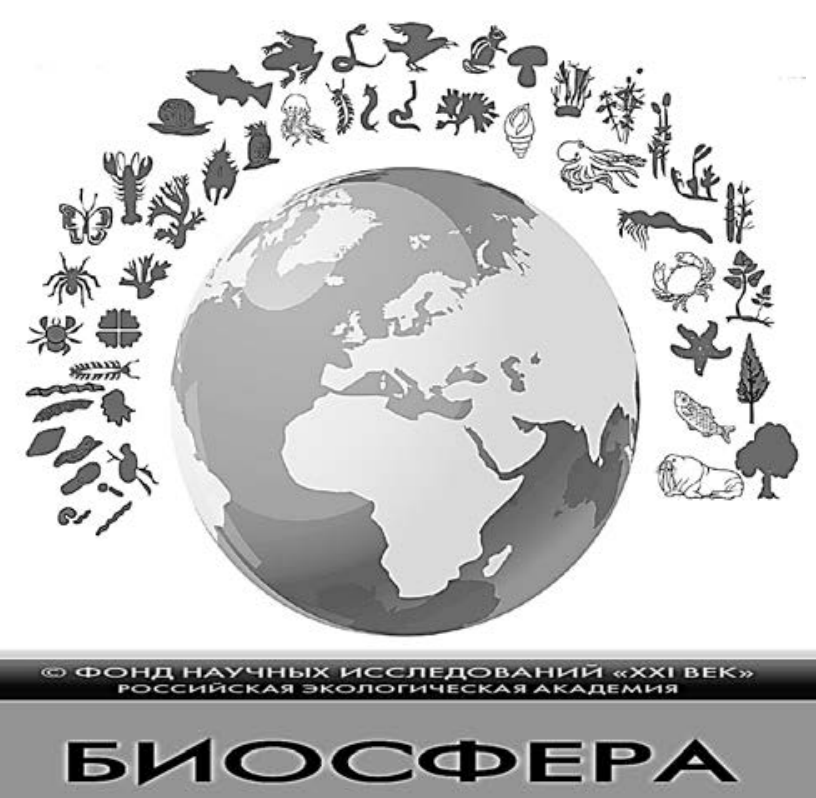